\title{
Instruction to Authors
}

1. "Journal of Nepal Chemical Society" (JNCS) publishes original research and review articles in Chemistry. The articles should be concise and clear. The medium of the journal will be English. Two copies of the manuscripts with electronic CD or floppy disk intended for publication should be forwarded to the Chief-Editor, Nepal Chemical Society, GPO Box 6145, Kathmandu, Nepal.

2. The submission of a paper will be held to imply that it represents the results of original research not previously published and that if accepted for JNCS it will not be published elsewhere. All papers are referred.

\section{General Presentation}

Manuscripts: The articles may be submitted either in the form of full length papers or short communications. The manuscript should be typed in double spacing on good quality paper $(35 \mathrm{~cm} \times 20 \mathrm{~cm})$. In general, there shall be not more than one review article per volume of the journal occasionally. Book reviews shall also be published.

4. A full length paper should usually be divided into the following parts: title, author's name and address of the institute, abstract (not exceeding more than $5 \%$ of the paper), introduction, experimental methods, results, discussion, conclusions and references. If necessary, results and discussion may be combined together. No such arrangements are required for short communication and review articles. However, they should be accompanied by abstracts. The title should be concise and appropriately informative for indexing.

5. Reference: In the text the reference should be cited with numerical. The italics and Latin word should be underlined. The reference citation should be done in the following way.

E. M. Lacobe and A. Stewart, J. Amer. Chem. Soc., 1961, 83, 3457.

A. I. Vogel, A text-book of practical organic chemistry including qualitative analysis, Longmans, 1961, p. 866.

D. Sarkar, Protein metabolisms in developing rat brain with special reference to carboxypetidase- $A$ and postnatal administration of excess aminoacid in developing rat brain. $\mathrm{Ph} . \mathrm{D}$. thesis, University of Calcutta, Calcutta, India, 1974, pp. 210. 
6. It should be clearly indicated in the text where the tables and figures should be inserted. Each table with explanatory notes and the figures legends should be typed on separate sheet of the paper.

7. Figures include photographs, drawing and graphs, and they should be clearly numbered with light pencils. The photographs should be preferably in black and white and in reproducible form. The drawings and graphs should be made in black ink on white paper or on tracing paper. Letters, symbols and numbers must appear clearly after the reproduction. The number of tables and figures should be kept as minimum as absolutely necessary for understanding the results.

8. The SI system units and symbols are recommended.

9. The mathematical formula should be carefully typed with symbols in correct alignment and adequately spaced. At least two clear lines should be left above and below all displayed equations. If special symbols be handwritten, they should be inserted with care and identified by pencil notes in the running text.

10. The authors will receive the proof of their articles for correction as far as possible. No new materials should be added during proof-reading and only print mistakes should be corrected. Generally accepted symbols of proof-reading are to be used.

11. The authors shall get one copy of the journal free of cost.

12. The editorial board will assume no responsibility for the statements and opinions forwarded by the contributors.

13. Further information may be provided on request to the Chief-Editor.

\section{Subscription rates}

$\begin{array}{ll}\text { Members } & \text { Free } \\ \text { Non-members } & \text { Rs } 100 /= \\ \text { For Indian } & \text { Rs } 100 /=(\text { I.C. }) \\ \text { For overseas countries } & \text { US } \$ 10 /=\end{array}$

NB: The paper published in this journal is abstracted by Chemical Abstract. 